\title{
Inhibition of exploratory behavior in the rat by handling
}

\author{
CARLO AMBROGI LORENZINI, CORRADO BUCHERELLI, ALDO GIACHETTI, \\ and GIOVANNA TASSONI \\ Università degli Studi di Firenze, Firenze, Italy
}

\begin{abstract}
The effect of tail-handling on exploratory behavior of the rat, measured as step-through latency in a well-lighted, two-box apparatus, was investigated. Male adult Wistar rats, aged 60 days, were employed in all three experiments. Experiment 1, in which the subjects were handled at different times after entering the goal chamber $(0,10,30,60,300$, and $600 \mathrm{sec})$, showed that immediate handling, relative to detention in the goal chamber (delay of handling) had an inhibitory effect on exploration. Experiment 2 showed that groups handled immediately after entering the goal chamber but then detained there for different durations all showed the same progressive inhibition of exploration. Experiment 3 showed that the inhibition of exploration (very long step-through latencies) due to tail-handling immediately after entering the goal chamber could be significantly decreased by further trials in which handling was delayed for a sufficient duration (30 sec or more). Handling is discussed as a stimulus that is aversive enough to elicit conditioned passive-avoidance responses (inhibition of exploratory behavior), although it is subject to rapid extinction.
\end{abstract}

In previous studies (Ambrogi Lorenzini, Bucherelli, \& Giachetti, 1986b, 1987), we showed that in a two-box apparatus, the exploratory activity of albino rats (Wistar strain), measured as step-through latency, was progressively inhibited in successive trials by the detention of the subjects in the starting chamber of the apparatus. This effect was quite evident even when the detention was very short $(10 \mathrm{sec})$. In the same studies, we also showed that the exploratory behavior of these subjects was inhibited by bright illumination of the apparatus. In another study, we showed that in the same brightly illuminated two-box apparatus employed in the above studies, goal-chamber detention influences the exploratory behavior of rats (Ambrogi Lorenzini, Bucherelli, \& Giachetti, 1986a). In fact, subjects immediately free to enter the goal chamber and allowed to remain undisturbed inside it for some time $(300 \mathrm{sec})$ exhibited very short step-through latencies; that is, they did not exhibit the inhibitory effects of bright illumination.

The present research was designed to determine the relationship between the facilitatory effect of goalchamber detention and its duration. At this point, it must be noted that detention inside the goal chamber implies that the handling necessary to return the subjects to the home cage will be delayed after the passage of the subjects from the starting chamber into the goal chamber. Therefore, we also tried to assess whether there are effects on step-through latency (exploration), besides those of goal-chamber detention, due to the time of handling.

The authors wish to express their thanks to S. Batacchi, S. Cammarata, M. Dolfi, and A. Vannucchi for their technical assistance. Correspondence may be addressed to Carlo Ambrogi Lorenzini, Dipartimento di Scienze Fisiologiche, Viale Morgagni 63, I-50134 Firenze, Italy.

\section{EXPERIMENT 1}

The aim of this experiment was to ascertain the effects of goal-chamber detentions of varying durations on the exploratory activity of subjects in a two-box apparatus, measured as step-through latency.

\section{Method}

Subjects. Seventy-two naive adult male Wistar rats, aged 60 days (purchased from Morini, Italy), served as subjects. The rats were housed singly. The animals received food and water ad lib. The animals were not handled by us before the experiment, and we ascertained that they had not received any previous gentling at the breeding facilities.

Apparatus. The two-box apparatus (Ambrogi Lorenzini, Bucherelli, \& Giachetti, 1987) consisted of two Plexiglas chambers of equal dimensions $(30 \times 21 \times 15 \mathrm{~cm})$ with stainless steel bar floors. The chambers were connected by a guillotine door $(8 \times 6 \mathrm{~cm})$. The walls of one of the chambers were solid white; those of the other chamber were vertically striped black and white (black stripe: $1.4 \mathrm{~cm}$; white stripe: $3 \mathrm{~cm}$ ). Both chambers were covered by transparent lids. The apparatus was placed in an acoustically insulated room and kept at a constant temperature $\left(20^{\circ} \pm 1^{\circ} \mathrm{C}\right)$. Lighting inside the apparatus was $60 \mathrm{~lx}$.

Procedure. In all trials, the subjects were manually taken out of the home cage by the tail (close to the root). Then they were placed inside a plastic container and were slid gently into the starting box of the apparatus. The same procedure (tail-handling) was repeated each time it was necessary to displace the subjects. Manual step-through latency measurements started immediately after closing the lid of the starting chamber, and were taken for up to $180 \mathrm{sec}$. Step-through latency was measured as the time it took the animal to place all four paws in the goal chamber. During this interval, the number of attempts to enter the goal chamber and instances of grooming were counted, and freezing was measured. Attempts were defined as incomplete passages into the goal chamber (up to three paws inside it). Freezing was defined as motor inhibition resulting in immobility, ending when voluntary movements were performed. 
All measurements were made by human observers. For all animals, the starting chamber was the solid white one, the striped one being the goal chamber. The experiment consisted of six consecutive daily trials. The animals underwent one trial each day, starting at 9:00 a.m. They were randomly divided into six groups of 12 subjects each. The subjects of the first group $\left(D_{0}\right)$ were not detained within the goal chamber. In fact, immediately after these subjects entered the goal chamber, or at the end of the 180 -sec period, they were returned to their respective home cages. The subjects of the other five groups (Groups $D_{10}, D_{30}, D_{60}, D_{300}$, and $D_{600}$ ), either after their spontaneous entry into the goal chamber or at the end of the 180-sec period, were detained inside the goal chamber for $10,30,60,300$, and $600 \mathrm{sec}$, respectively, before being returned to their home cages. The results of the experiment were analyzed by means of two-way analysis of variance (ANOVA) with repeated measures on trials. Paired comparisons between groups were performed by means of post hoc Tukey tests (Tukey, 1949). Step-through latencies on Trial 1 of all subjects were subjected to independent statistical analysis, since these latencies were measured before group differentiation according to the duration of goal-chamber detention.

\section{Results}

Step-through latency. As shown in Figure 1, in Trials 26 , the $D_{0}$ subjects exhibited a progressively greater increase in step-through latency than any other group. The results were analyzed by means of a groups $(6) \times$ trials (5) ANOVA. There were significant differences between groups $[F(5,66)=5.24, p<.001]$ and between trials $[F(4,264)=41.64, p<.001]$, and significant interactions between groups and trials $[F(20,264)=1.76, p<.05]$. By means of the Tukey test, significant differences were found between Group $D_{0}$ and all other groups (Group $D_{0}$ vs. Groups $\mathrm{D}_{10}$ and $\mathrm{D}_{30}, p<.05$; Group $\mathrm{D}_{0}$ vs. Groups $\mathrm{D}_{60}, \mathrm{D}_{300}$, and $\left.\mathrm{D}_{600}, p<.01\right)$. Among the detained groups, significant differences were found between Group $\mathrm{D}_{600}$ and both Group $\mathrm{D}_{10}$ and Group $\mathrm{D}_{30}(p<.05)$, the latter groups having significantly longer latencies. On Trial 6, there were significant differences in step-through latency between Groups $\mathrm{D}_{0}$ and $\mathrm{D}_{30}(p<.05)$, Groups $\mathrm{D}_{0}$ and $\mathrm{D}_{60}(p<.05)$, Groups $\mathrm{D}_{0}$ and $\mathrm{D}_{300}(p<.05)$, Groups $\mathrm{D}_{0}$ and $\mathrm{D}_{600}(p<.01)$, and Groups $\mathrm{D}_{10}$ and $\mathrm{D}_{600}$ $(p<.05)$.

Attempts. As shown in Table 1, in general, the mean number of attempts increased from Trial 2 to Trial 6. $D_{0}$ subjects exhibited the highest number of attempts. A groups (6) $\times$ trials (5) ANOVA showed that there were significant differences between groups $[F(5,66)=2.68$, $p<.05]$ and between trials $[F(4,264)=6.89, p<.001]$, but there was no interaction between groups and trials. By means of the Tukey test, significant differences were found between Group $D_{0}$ and both Group $D_{30}$ and Group $\mathrm{D}_{60}(p<.05)$, and between Group $\mathrm{D}_{0}$ and both Group $\mathrm{D}_{10}$ and Group $\mathrm{D}_{600}(p<.01)$.

Grooming. As shown in Table 1 , in general, the mean number of instances of grooming increased from Trial 2 to Trial 6. $D_{0}$ subjects exhibited the most grooming. A groups (6) $\times$ trials (5) ANOVA showed that there were significant differences between groups $[F(5,66)=2.44$, $p<.05]$ and also between trials $[F(4,264)=5.68$, $p<.001$, but there was no interaction between groups and trials. By means of the Tukey test, significant differ-

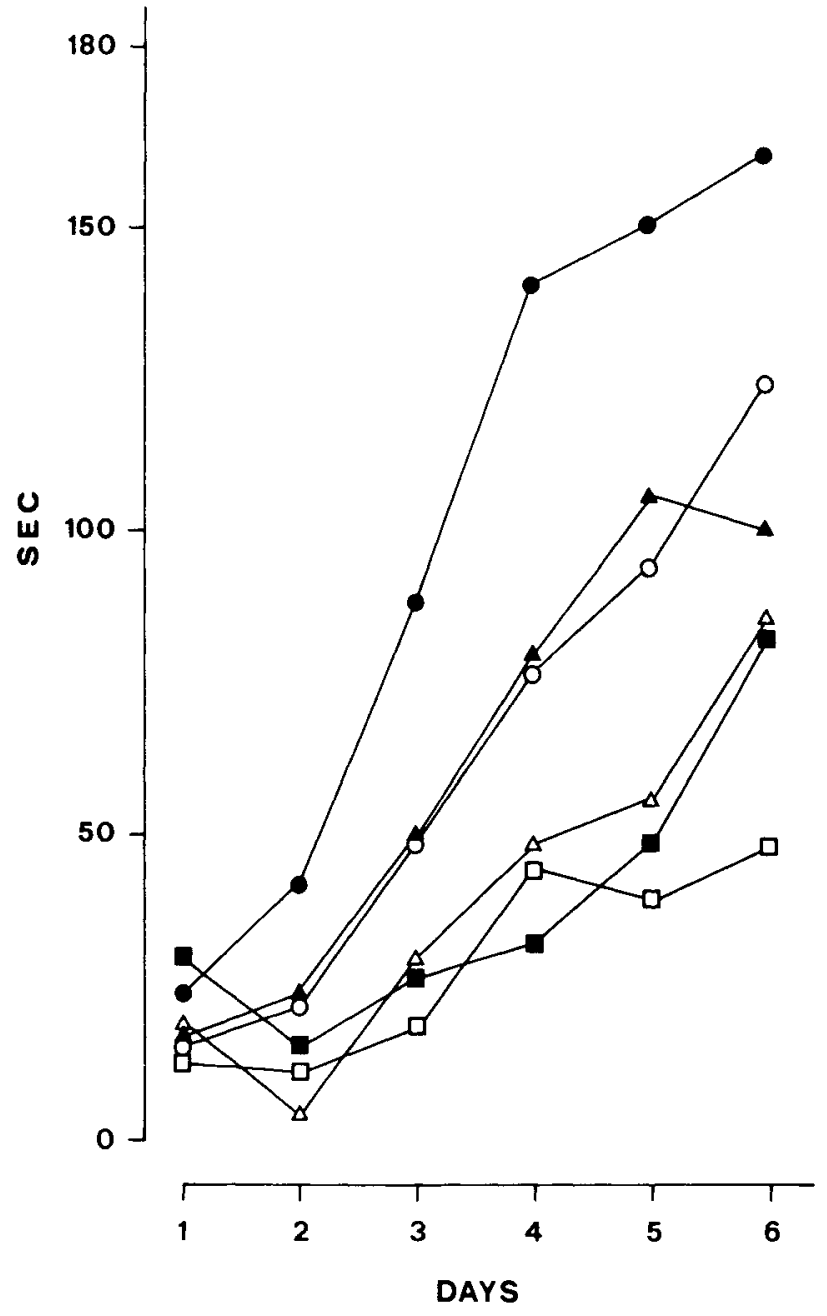

Figure 1. Mean daily step-through latencies of undetained $\left(D_{0}, \bullet\right)$ and detained $\left(D_{10}, O ; D_{30}, \Delta ; D_{60}, \triangle ; D_{300}, \square ;\right.$ and $\left.D_{600}, \square\right)$ groups of subjects in Experiment 1.

ences were found between Group $D_{0}$ and both Group $D_{60}$ and Group $\mathrm{D}_{600}(p<.05)$.

Freezing. No freezing was observed in any of the subjects during the interval prior to the step-through response.

\section{Discussion}

The findings of this experiment show that in the undetained subjects (i.e., in the subjects handled immediately after entering the goal chamber), step-through latency increased progressively and significantly from Trial 2 to Trial 6. This finding means that, in these subjects, exploratory behavior was inhibited. In addition, detention in the goal chamber influenced the inhibition of exploratory behavior significantly, even when detention lasted for only a very short period $(10 \mathrm{sec})$. Moreover, an increase in the duration of goal-chamber detention heightened the effect. It must be emphasized that only exploratory behavior was inhibited; locomotion and/or other activities remained unaltered, since the subjects performed both attempts and grooming responses and did not exhibit freezing in the starting box. Thus, detention influenced 
Table 1

Mean $( \pm S E)$ Number of Attempts and Groomings of Undetained $\left(D_{0}\right)$ and Detained $\left(D_{10}, D_{30}, D_{60}, D_{300}\right.$, and $\left.D_{600}\right)$ Groups of Subjects in Experiment 1

\begin{tabular}{|c|c|c|c|c|c|c|c|c|c|c|c|c|}
\hline \multirow[b]{2}{*}{ Trial } & \multicolumn{2}{|c|}{$D_{0}$} & \multicolumn{2}{|c|}{$\mathrm{D}_{10}$} & \multicolumn{2}{|c|}{$D_{30}$} & \multicolumn{2}{|c|}{$D_{s 0}$} & \multicolumn{2}{|c|}{$D_{300}$} & \multicolumn{2}{|c|}{$D_{600}$} \\
\hline & $M$ & $S E$ & $M$ & $S E$ & $M$ & $S E$ & $M$ & $S E$ & $M$ & $S E$ & $M$ & $S E$ \\
\hline \multicolumn{13}{|c|}{ Attempts } \\
\hline 1 & 0.00 & 0.00 & 0.00 & 0.00 & 0.00 & 0.00 & 0.00 & 0.00 & 0.17 & 0.11 & 0.00 & 0.00 \\
\hline 2 & 0.33 & 0.26 & 0.00 & 0.00 & 0.08 & 0.08 & 0.00 & 0.00 & 0.17 & 0.17 & 0.83 & 0.83 \\
\hline 3 & 1.25 & 0.49 & 0.17 & 0.17 & 0.67 & 0.43 & 0.17 & 0.11 & 0.75 & 0.35 & 0.17 & 0.17 \\
\hline 4 & 1.50 & 0.42 & 0.67 & 0.41 & 0.67 & 0.28 & 0.33 & 0.19 & 1.08 & 0.53 & 0.17 & 0.17 \\
\hline 5 & 1.50 & 0.38 & 0.92 & 0.38 & 1.08 & 0.48 & 1.00 & 0.46 & 0.58 & 0.26 & 0.41 & 0.26 \\
\hline 6 & 1.83 & 0.64 & 0.83 & 0.42 & 1.00 & 0.30 & 1.08 & 0.40 & 1.17 & 0.59 & 0.58 & 0.29 \\
\hline \multicolumn{13}{|c|}{ Groomings } \\
\hline 1 & 0.00 & 0.00 & 0.00 & 0.00 & 0.00 & 0.00 & 0.00 & 0.00 & 0.00 & 0.00 & 0.00 & 0.00 \\
\hline 2 & 0.33 & 0.33 & 0.00 & 0.00 & 0.25 & 0.25 & 0.00 & 0.00 & 0.00 & 0.00 & 0.00 & 0.00 \\
\hline 3 & 0.58 & 0.23 & 0.33 & 0.33 & 0.58 & 0.40 & 0.00 & 0.00 & 0.33 & 0.26 & 0.33 & 0.19 \\
\hline 4 & 1.50 & 0.48 & 0.58 & 0.50 & 0.83 & 0.83 & 0.00 & 0.00 & 0.58 & 0.40 & 0.83 & 0.83 \\
\hline 5 & 1.08 & 0.34 & 0.83 & 0.47 & 0.75 & 0.42 & 0.17 & 0.17 & 0.83 & 0.61 & 0.17 & 0.11 \\
\hline 6 & 1.42 & 0.38 & 1.08 & 0.60 & 0.91 & 0.40 & 0.17 & 0.11 & 0.58 & 0.34 & 0.17 & 0.11 \\
\hline
\end{tabular}

the exploratory behavior of the rats. Is this effect due to detention, or to the delay in handling before putting the rats back into the home cage? To answer this question we devised the following experiment.

\section{EXPERIMENT 2}

The aim of this experiment was to ascertain whether the effects of goal-chamber detention on step-through latency could be modified in any way by handling the subjects as soon as they were inside the goal chamber; that is, all of the subjects were to be tail-handled at the beginning of the detention period.

\section{Method}

Subjects. Seventy-two naive male Wistar rats, aged 60 days (purchased from Morini, Italy), served as subjects. The rats were housed singly. The animals received food and water ad lib. The animals were not handled by us before the experiment, and we ascertained that they had not received any previous gentling at the breeding facilities.

Apparatus. The apparatus used in Experiment 1 was used in the present experiment.

Procedure. As in Experiment 1, the experiment consisted of six consecutive daily trials. The animals were randomly divided into six groups of 12 rats each. The animals underwent one trial each day, starting at 9:00 a.m. For all animals, the starting chamber was the solid white one, the striped one being the goal chamber. The subjects of the first group $\left(\mathrm{HnD}_{0}\right)$ were not detained inside the goal chamber. As in Experiment 1, the subjects of the other five groups were detained inside the goal chamber by closing the connecting door, for $10,30,60,300$, and $600 \mathrm{sec}$, respectively, before returning them to their home cages (Groups $\mathrm{HnD}_{10}, \mathrm{HnD}_{30}, \mathrm{HnD}_{60}$, $\mathrm{HnD}_{300}$, and $\left.\mathrm{HnD}_{600}\right)$. After either spontaneously entering the goal chamber or being placed inside it at the end of the 180-sec allowed latency, the subjects were immediately taken out by the tail (handling) and then put into the goal chamber again.

Step-through latencies of all subjects in Trial 1 were subjected to independent statistical analysis, since these latencies were measured before group differentiation according to the duration of goalchamber detention. The results were subjected to the same statistical analysis employed in Experiment 1.

\section{Results}

Step-through latency. As shown in Figure 2, in Trials 2-6, all groups of subjects exhibited a similar progressive increase in step-through latency. These results were analyzed by means of a groups $(6) \times$ trials $(5)$ ANOVA. There were no significant differences between groups $[F(5,66)=0.66]$, but there were significant differences between trials $[F(4,264)=129.09, p<.001]$, and there was no interaction between groups and trials.

Attempts. As shown in Table 2, in general, the mean number of attempts increased from Trial 2 to Trial 6. A groups (6) $\times$ trials (5) ANOVA showed that there were no significant differences between groups $[F(5,66)=2.04]$, but there were significant differences between trials $[F(4,264)=15.43, p<.001]$. There was no interaction between groups and trials.

Grooming. As shown in Table 2, in general, the mean number of incidents of grooming increased from Trial 2 to Trial 6. A groups (6) $\times$ trials (5) ANOVA showed that there were no significant differences between groups $[F(5,66)=0.41]$, but there were significant differences between trials $[F(4,264)=3.32, p<.01]$. There was no interaction between groups and trials.

Freezing. No freezing was observed in any of the subjects during the interval prior to the step-through response.

\section{Discussion}

The findings of the present experiment show that the effects of goal-chamber detention do not appear if the subjects are handled at Time 0 (i.e., as soon as they are inside the goal chamber). In all groups, irrespective of detention duration, exploratory behavior was inhibited, as it was in the $\mathrm{D}_{0}$ group in Experiment 1. Again, as in Experiment 1 , only exploratory behavior was inhibited, other motor activities being unaffected. No freezing was observed. Thus, it appears that it is the act of handling in close temporal contiguity to stepping through that causes the inhibition, and that the results of Experiment 1 must 


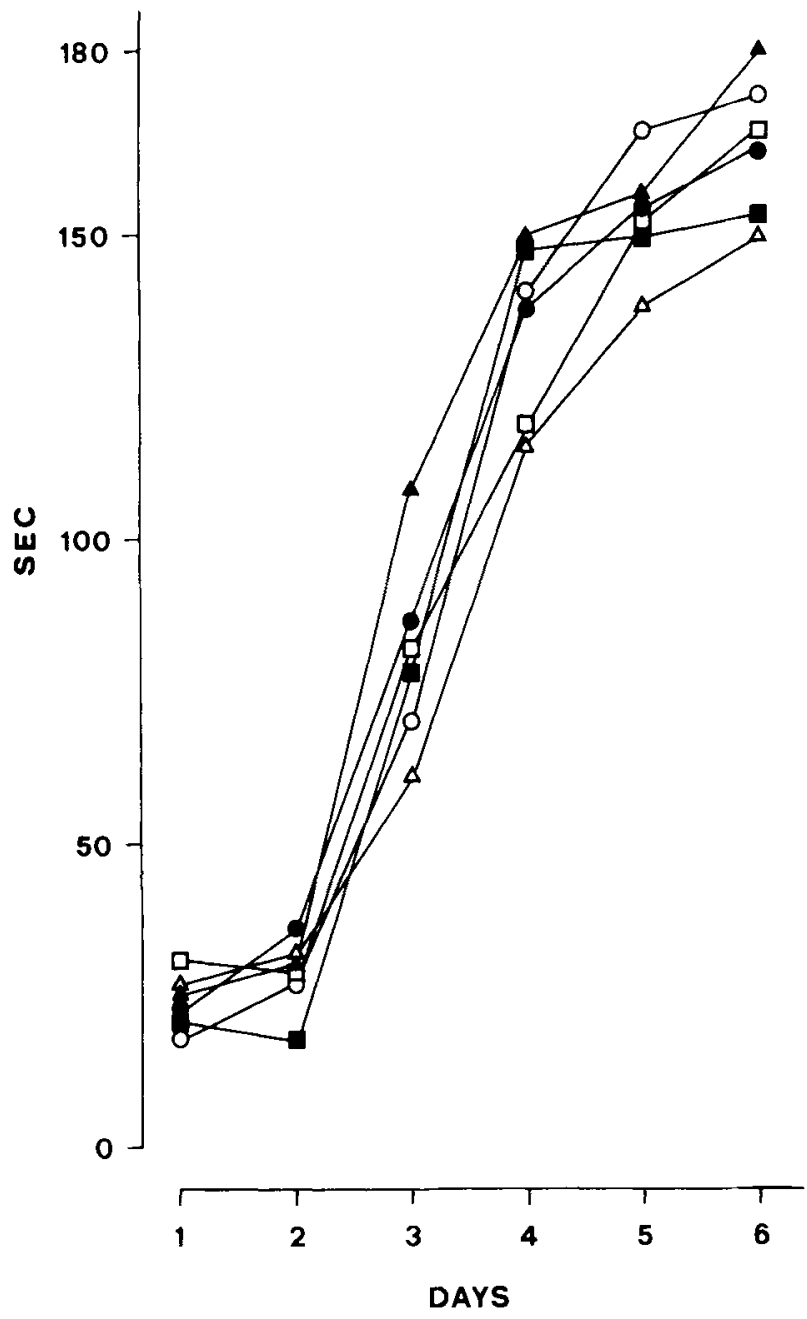

Figure 2. Mean daily step-through latencies of undetained $\left(\mathrm{HnD}_{0}, \bullet\right)$ and detained $\left(\mathrm{HnD}_{10}, \mathrm{O} ; \mathrm{HnD}_{30}, \Delta ; \mathrm{HnD}_{60}, \triangle ; \mathrm{HnD}_{300}, \mathbf{v}\right.$; and $\left.\mathrm{HnD}_{\mathrm{cos}}, \square\right)$ groups of subjects in Experiment 2. be understood as due to the delay in handling rather than to the detention in the goal chamber per se. Since the inhibition of exploratory behavior increased with repeated trials, and since this inhibition appeared only when stepping through and handling were temporally close, this inhibition appears to have the characteristic features of a conditioned response. One more question may arise: Is this response also subject to extinction?

\section{EXPERIMENT 3}

The aim of this experiment was to determine if the effects of handling, once established, can be influenced by subsequent goal-chamber detention. To ascertain this, five initial trials were administered. During these trials, the animals were handled immediately after entering the goal chamber. Six further trials were then carried out. In these trials, one group of rats continued to be handled as before, and the other five groups of animals were detained in the goal chamber for different lengths of time.

\section{Method}

Subjects. Sixty naive male Wistar rats, aged 60 days (purchased from Morini, Italy), served as subjects. The rats were housed singly. The animals received food and water ad lib. They were not handled by us before the experiment, and we ascertained that they had not received any previous gentling at the breeding facilities.

Apparatus. The apparatus used in Experiments 1 and 2 was used in the present experiment.

Procedure. The animals were randomly divided into six groups of 10 rats each. The experiment consisted of 11 consecutive daily trials. The animals underwent one trial each day, starting at 9:00 a.m. On Trials 1-5, the subjects of all groups underwent the same treatment as the $D_{0}$ subjects in Experiment 1 (i.e., they were handled by the tail and returned to their home cages as soon as they entered the goal chamber, or at the end of the 180 -sec period). From Trial 6 to Trial 11, the subjects of the first group $\left(D_{0}-0\right)$ were not detained inside the goal chamber, but underwent the same proce-

Table 2

Mean $( \pm S E)$ Number of Attempts and Groomings of Undetained $\left(\mathrm{HnD}_{0}\right)$ and Detained ( $\mathrm{HnD}_{10}, \mathrm{HnD}_{30}, \mathrm{HnD}_{60}, \mathrm{HnD}_{300}$, and $\mathrm{HnD}_{600}$ ) Groups of Subjects in Experiment 2

\begin{tabular}{|c|c|c|c|c|c|c|c|c|c|c|c|c|}
\hline \multirow[b]{2}{*}{ Trial } & \multicolumn{2}{|c|}{$\mathrm{HnD}_{0}$} & \multicolumn{2}{|c|}{$\mathrm{HnD}_{10}$} & \multicolumn{2}{|c|}{$\mathrm{HnD}_{30}$} & \multicolumn{2}{|c|}{$\mathrm{HnD}_{60}$} & \multicolumn{2}{|c|}{$\mathrm{HnD}_{300}$} & \multicolumn{2}{|c|}{$\mathrm{HnD}_{600}$} \\
\hline & $M$ & $S E$ & $M$ & $S E$ & $M$ & $S E$ & $M$ & $S E$ & $M$ & $S E$ & $M$ & $S E$ \\
\hline \multicolumn{13}{|c|}{ Attempts } \\
\hline 1 & 0.00 & 0.00 & 0.00 & 0.00 & 0.83 & 0.38 & 0.00 & 0.00 & 0.08 & 0.08 & 0.17 & 0.17 \\
\hline 2 & 0.50 & 0.23 & 0.17 & 0.11 & 0.17 & 0.11 & 0.83 & 0.83 & 0.00 & 0.00 & 0.83 & 0.83 \\
\hline 3 & 1.08 & 0.40 & 1.08 & 0.45 & 0.83 & 0.38 & 0.50 & 0.29 & 0.92 & 0.36 & 0.58 & 0.29 \\
\hline 4 & 1.40 & 0.45 & 2.08 & 0.66 & 0.33 & 0.14 & 1.00 & 0.39 & 1.58 & 0.36 & 1.33 & 0.33 \\
\hline 5 & 1.40 & 0.50 & 2.42 & 0.63 & 0.91 & 0.40 & 0.92 & 0.31 & 1.33 & 0.19 & 2.08 & 0.72 \\
\hline 6 & 1.58 & 0.54 & 2.00 & 0.55 & 1.17 & 0.34 & 0.92 & 0.31 & 1.25 & 0.28 & 1.83 & 0.60 \\
\hline \multicolumn{13}{|c|}{ Groomings } \\
\hline 1 & 0.00 & 0.00 & 0.00 & 0.00 & 0.00 & 0.00 & 0.00 & 0.00 & 0.00 & 0.00 & 0.42 & 0.42 \\
\hline 2 & 0.50 & 0.26 & 0.00 & 0.00 & 0.25 & 0.18 & 0.25 & 0.25 & 0.83 & 0.83 & 0.83 & 0.83 \\
\hline 3 & 0.50 & 0.23 & 0.50 & 0.36 & 0.42 & 0.26 & 0.17 & 0.17 & 0.50 & 0.26 & 0.33 & 0.33 \\
\hline 4 & 0.58 & 0.29 & 0.58 & 0.29 & 0.42 & 0.26 & 0.58 & 0.34 & 0.75 & 0.25 & 0.67 & 0.28 \\
\hline 5 & 0.58 & 0.29 & 0.58 & 0.23 & 0.33 & 0.19 & 0.42 & 0.15 & 0.91 & 0.34 & 1.08 & 0.43 \\
\hline 6 & 0.57 & 0.26 & 0.33 & 0.19 & 0.33 & 0.26 & 0.75 & 0.30 & 0.42 & 0.19 & 0.42 & 0.19 \\
\hline
\end{tabular}


dure as in Trials 1-5. The subjects of the other five groups were detained in the goal chamber for $10,30,60,300$, and $600 \mathrm{sec}$, respectively (Groups $D_{0}-10, D_{0}-30, D_{0}-60, D_{0}-300$, and $D_{0}-600$ ).

The results were subjected to the same statistical analysis as in Experiments 1 and 2, and in the same way, step-through latencies of all subjects in Trial 1 were subjected to independent statistical analysis. In Trial 6, step-through latencies of all subjects were statistically treated together with those in Trials $2-5$, since they were obtained before group differentiation according to the duration of goal-chamber detention. In addition, latencies of Trials 7-11 were combined for statistical analysis.

\section{Results}

Step-through latency. As shown in Figure 3, in Trials 2-6 (before any of the subjects were detained in the goal chamber), all groups exhibited a similar progressive increase in step-through latency. The results were analyzed by means of a groups $(6) \times$ trials $(5)$ ANOVA. There were no significant differences between groups $[F(5,54)=0.30]$, but there were significant differences between trials $[F(4,216)=107.67, p<.001]$. There was no interaction between groups and trials. As shown in Figure 3, following the detention of five of the groups of subjects in the goal chamber, there were differences in step-through latency, which were already present on Trial 7, and which were maintained up to Trial 11. Stepthrough latency values in Groups $D_{0}-0$ and $D_{0}-10$ remained the highest, whereas latency values in Group $D_{0}-600$ (longest detention) were always the lowest. These results were analyzed by means of a groups (6) $\times$ trials (5) ANOVA. There were significant differences between groups $[F(5,54)=4.63, p<.01]$, but there was neither a significant difference between trials $[F(4,216)=1.16]$ nor a significant interaction between groups and trials. The Tukey test showed that there were significant differences between Group $\mathrm{D}_{0}-0$ and Groups $\mathrm{D}_{0}-30, \mathrm{D}_{0}-60$, and $\mathrm{D}_{0}-300(p<.05)$, or between Group $\mathrm{D}_{0}-0$ and Group $D_{0}-600(p<.01)$. With respect to detained groups, there were significant differences between Group $D_{0}-600$ and Group $\mathrm{D}_{0}-10(p<.01)$, and between Group $\mathrm{D}_{0}-600$ and Groups $D_{0}-60$ and $D_{0}-300(p<.05)$. For individual groups, a significant difference of step-through latency between Trials 6 and 11 was found for Group $D_{0}-300$ $(p<.05)$ and Group $\mathrm{D}_{0}-600(p<.01)$.

Attempts. As shown in Table 3, in all groups of subjects, the mean number of attempts increased from Trial 2 to Trial 6. A groups (6) $\times$ trials (5) ANOVA showed that there were no significant differences between groups $[F(5,54)=0.39]$, but there were significant differences between trials $[F(4,216)=23.19, p<.001]$. There was no interaction between groups and trials. There were no marked differences between groups in the mean number of attempts from Trial 7 to Trial 11 (not shown). A groups (6) $\times$ trials (5) ANOVA of the attempts from Trial 7 to Trial 11 showed that there were no significant differ-

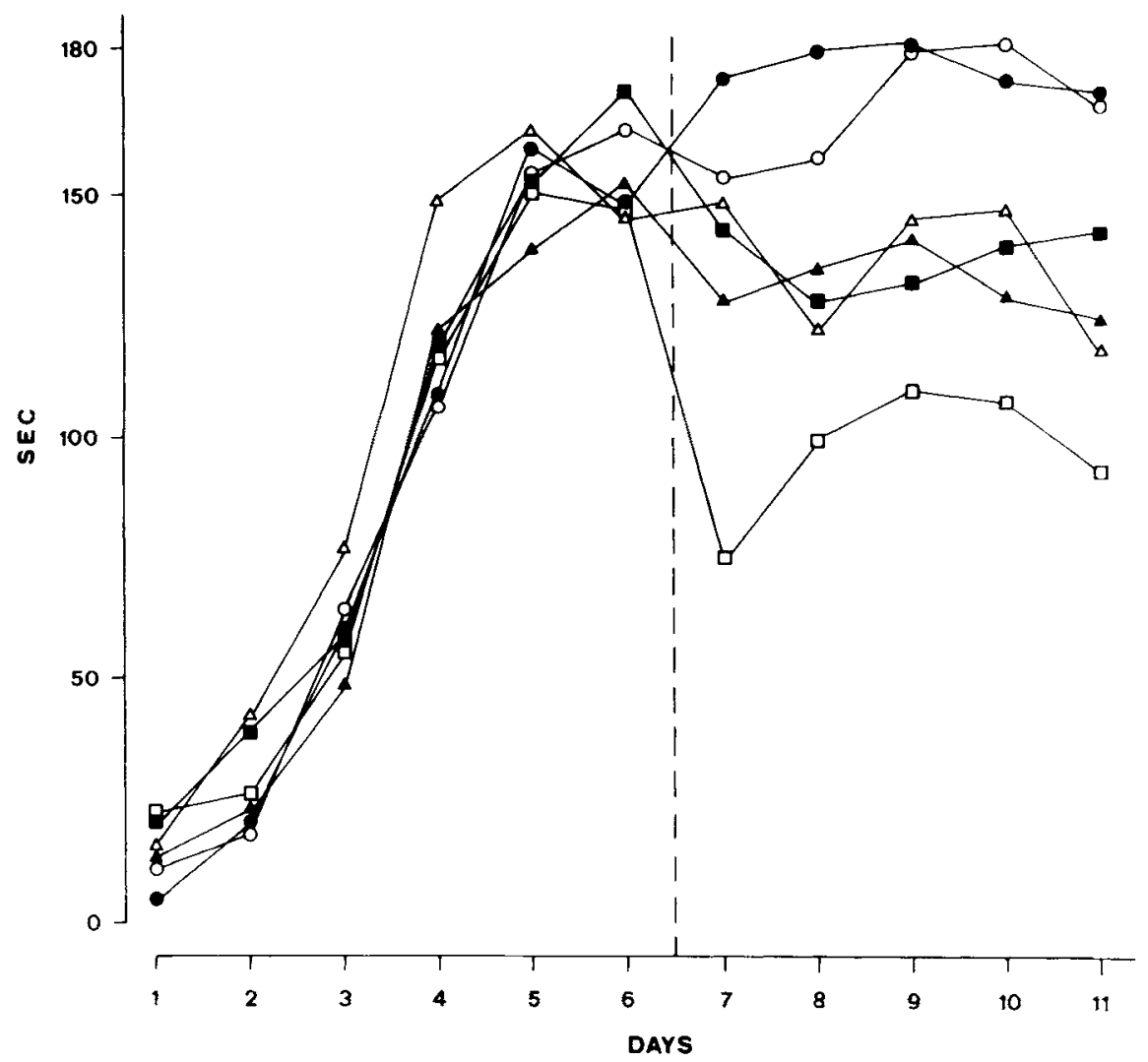

Figure 3. Mean daily step-through latencies of undetained $\left(\mathrm{D}_{0}-\mathbf{0}, \bullet\right)$ and detained $\left(\mathrm{D}_{0}-10,0 ; \mathrm{D}_{0}-30\right.$, $\Delta ; D_{0}-60, \triangle ; D_{0}-300, \square ;$ and $\left.D_{0}-600, \square\right)$ groups of subjects in Experiment 3. 
Table 3

Mean $( \pm S E$ ) Number of Attempts and Groomings of all Groups of Subjects in Experiment 3

\begin{tabular}{|c|c|c|c|c|c|c|c|c|c|c|c|c|}
\hline \multirow{2}{*}{ Trial } & \multicolumn{2}{|c|}{$D_{0}-0$} & \multicolumn{2}{|c|}{$D_{0}-10$} & \multicolumn{2}{|c|}{$D_{0}-30$} & \multicolumn{2}{|c|}{$D_{0}-60$} & \multicolumn{2}{|c|}{$D_{0}-300$} & \multicolumn{2}{|c|}{$D_{0}-600$} \\
\hline & $M$ & $S E$ & $M$ & $S E$ & $M$ & $S E$ & $M$ & $S E$ & $M$ & $S E$ & $M$ & $S E$ \\
\hline \multicolumn{13}{|c|}{ Attempts } \\
\hline 1 & 0.10 & 0.10 & 0.00 & 0.00 & 0.00 & 0.00 & 0.00 & 0.00 & 0.00 & 0.00 & 0.00 & 0.00 \\
\hline 2 & 0.10 & 0.10 & 0.10 & 0.10 & 0.00 & 0.00 & 0.40 & 0.40 & 0.40 & 0.30 & 0.30 & 0.21 \\
\hline 3 & 0.70 & 0.40 & 0.50 & 0.22 & 0.20 & 0.13 & 0.70 & 0.26 & 0.30 & 0.21 & 0.50 & 0.31 \\
\hline 4 & 0.90 & 0.40 & 1.00 & 0.39 & 1.80 & 0. & 2.10 & 0.62 & 1.30 & 7 & 1.60 & 0.72 \\
\hline 5 & 2.60 & $0.8 \mathrm{c}$ & 1.50 & 0.48 & 2.20 & 0.63 & 1.90 & 0.60 & 1.70 & 0.49 & 1.60 & 0.75 \\
\hline 6 & 1.70 & 0.30 & 2.50 & 0.85 & 3.80 & 1.23 & 2.30 & 0.56 & 1.40 & 0.43 & 2.20 & 0.53 \\
\hline \multicolumn{13}{|c|}{ Groomings } \\
\hline 1 & 0.00 & 0.00 & 0.00 & 0.00 & 0.00 & 0.00 & 0.00 & 0.00 & 0.00 & 0.00 & 0.00 & 0.00 \\
\hline 2 & 0.00 & 0.00 & 0.10 & 0.10 & 0.00 & 0.00 & 0.00 & 0.00 & 0.30 & 0.21 & 0.00 & 0.00 \\
\hline 3 & 0.10 & 0.10 & 1.10 & 0.72 & 0.40 & 0.27 & 0.10 & 0.10 & 0.30 & 0.30 & 0.50 & 0.34 \\
\hline 4 & 0.60 & 0.27 & 0.60 & 0.50 & 0.80 & 0.42 & 0.90 & 0.41 & 0.60 & 0.34 & 0.50 & 0.31 \\
\hline 5 & 0.90 & 0.38 & 0.60 & 0.22 & 1.20 & 0.55 & 0.90 & 0.38 & 0.70 & 0.43 & 0.90 & 0.41 \\
\hline 6 & 1.20 & 0.51 & 0.90 & 0.35 & 1.20 & 0.51 & 0.90 & 0.31 & 0.80 & 0.29 & 0.40 & 0.31 \\
\hline
\end{tabular}

ences between either groups $[F(5,54)=1.73]$ or trials $[F(4,216)=1.31]$, and there was no interaction between groups and trials.

Grooming. As shown in Table 3, in all groups of subjects, the mean number of instances of grooming increased from Trial 2 to Trial 6 . A groups (6) $\times$ trials (5) ANOVA showed that there were no significant differences between groups $[F(5,54)=0.13]$, but there were significant differences between trials $[F(4,216)=9.13, p<.001]$. There were no significant interactions between groups and trials. There were no marked differences between groups in the mean number of instances of grooming from Trial 7 to Trial 11 (not shown). A groups (6) $\times$ trials (5) ANOVA on the grooming data from Trial 7 to Trial 11 showed that there were no significant differences either between groups $[F(5,54)=1.38]$ or between trials $[F(4,216)=0.27]$, and there was no interaction between groups and trials.

Freezing. No freezing was observed in any of the subjects during the interval prior to the step-through response.

\section{Discussion}

The results of this experiment show that the inhibition of exploratory behavior, once established after several consecutive trials, was maintained through the end of the experiment in Group $D_{0}-0$, which therefore becomes the internal control of the time course of exploratory inhibition in undetained rats. After detention in the goal chamber, in some of the other groups, there was a trend toward a diminution of inhibition, which reached statistical significance in Groups $D_{0}-300$ and $D_{0}-600$. In other words, the diminution of inhibition is all the more evident the longer the detention. Therefore, this inhibition of exploratory behavior-a conditioned response-also is subject to extinction.

\section{ANCILLARY FINDINGS}

Statistical analysis of some of the data of Experiments 1, 2 , and 3 shows that: (1) there were no significant differ- ences between the values of step-through latency in Trial 1 for all 204 subjects of the 18 groups employed $[F(17,186)=$ $0.91]$ - that is, there were no differences in the exploratory activity of naive subjects; and (2) concerning step-through latency values of Trials 2-6 in Group $D_{0}$ of Experiment 1, and in all groups for Experiments 2 and 3, analyzed by means of a groups (13) $\times$ trials (5) ANOVA, there were no significant differences between groups $[F(12,131)=$ $0.56]$, but there were significant differences between trials $[F(4,524)=244.48, p<.001]$. There was no interaction between groups and trials; that is, all animals handled at Time 0 (as soon as they were inside the goal chamber) exhibited the same inhibition of exploratory behavior.

\section{GENERAL DISCUSSION}

The apparatus employed in the present work was described in a previous study (Ambrogi Lorenzini, Bucherelli, \& Giachetti, 1987). In that study, it was shown that the black striping in the walls of one of the two chambers did not bias the exploratory performance of Wistar rats. As in our previous reports, step-through latency was taken as a measure of exploratory activity in a two-box apparatus. Given the dimensions of the apparatus, the floor of which is not marked by lines or divided into squares, we feel that this measurement is unequivocal and easily carried out. In fact, even though it may be true that the passage from the starting box into the goal box does not exhaust the exploratory repertoire of the rat, nonetheless, the passage through a well-defined physical boundary, without punishment or reward, is essential for the exploration of the goal compartment. The initial exploratory behavior (short step-through latency) of all subjects employed in the present three experiments confirms the neophilia (also called "neotic approach preference" by Corey, 1978) of domestic (Wistar) rats in free-exploratory tests (Hirate, Kuribara, \& Takodoro, 1988).

The statistical analysis shows that the step-through latencies of Experiment 1 fall into three subdivisions: 
Group $D_{0}$, Groups $D_{10}$ and $D_{30}$, and Groups $D_{60}, D_{300}$, and $\mathrm{D}_{600}$. As already noted, in all groups, there was an increase in step-through latency from Trial 2 to Trial 6, but with significant quantitative differences among the three subdivisions. In the groups with longer detention $\left(D_{60}, D_{300}\right.$, and $\left.D_{600}\right)$, the observed increase of stepthrough latency or inhibition of exploration may be taken as describing the decline of the approach tendency of these subjects with repeated stimulus exposure (habituation, familiarity; see Ambrogi Lorenzini, Bucherelli, \& Giachetti, 1987; Berlyne, 1950, 1955; Rabedeau \& Miles, 1959). This finding has been recently confirmed (Hirate et al., 1988) as a constant feature of albino rat behavior. This conclusion is supported by the fact that in these groups, there was not a sufficiently close temporal contiguity between two events-stepping through and handling-for handling to markedly affect stepping through. This argument does not apply to the other groups of subjects. In fact, both the maximal increase in step-through latency (inhibition of exploration) exhibited by Group $D_{0}$ and the lesser increase shown by Groups $D_{10}$ and $D_{30}$ were significantly greater than those of the other three groups. Indeed, in Groups $D_{0}, D_{10}$, and $D_{30}$, stronger effects of habituation than those measured in Groups $D_{60}, D_{300}$, and $D_{600}$ cannot be expected when the time spent inside the apparatus (in particular inside the goal box) is shorter. Furthermore, in the three groups with shorter goal-box detention, and especially in Group $D_{0}$, the duration of the between-events interval was short enough to allow the acquisition of a conditioned response. Therefore, the increased step-through latency (inhibition of exploration) in Groups $D_{0}, D_{10}$, and $D_{30}$ can be understood as a conditioned aversive response due to tail-handling (the aversive event) taking place in close temporal contiguity to stepping through.

This conclusion is supported by the results of Experiment 2 , in which, after the handling of all subjects at Time 0 , the between-groups differences observed in Experiment 1 did not appear, the subsequent detention inside the goal box notwithstanding. In fact, the inhibition of exploratory behavior exhibits two characteristics of a conditioned response: (1) it increases with repetition of the trials, and (2) as shown by the results of Experiment 3, the inhibition of exploratory behavior undergoes extinction when the interval between stepping through and the aversive event becomes sufficiently long. Therefore, it can be concluded that even events such as handling, which are far less severe than footshocks, are sufficiently aversive to cause a passive-avoidance response.

In the present study, as in a previous one (Ambrogi Lorenzini, Bucherelli, \& Giachetti, 1987), the number of attempts (i.e., incomplete passages from the starting box into the goal chamber) and instances of grooming were recorded during the interval prior to the step-through response. The findings of the present study are in full accord with those of the previous one. In fact, the number of attempts and/or instances of grooming was related to the step-through latency: the longer the step-through la- tency, the more attempts or instances of grooming were performed. This is also shown by the fact that, for these activities, significant differences between groups were found only when there were significant differences for step-through latency. It must be emphasized that in the present context, the performances of grooming and attempts are not important per se, but are important on two different qualitative counts. First, they are important because both activities are definite signs of conflict between the innate exploratory drive and the aversive effect of handling. The second, equally important reason is possibly more interesting: these activities are a proof of the selective inhibition of exploratory behavior. In fact, given that the animal performs complex motor activities prior to making the step-through response, the inhibition of exploration cannot be due to a generalized motor inhibition (freezing).

The inhibitory response (passive avoidance) is quite clear-cut but much less strong than that obtained, for instance, with the use of even mild footshocks (Ambrogi Lorenzini, Bucherelli, Giachetti, \& Tassoni, 1987). In fact, freezing was absent in all of the subjects in the three experiments in the present study while they were inside the starting chamber. In contrast, freezing is conspicuously present in animals subjected to footshocks (Ambrogi Lorenzini, Bucherelli, Giachetti, \& Tassoni, 1987). In addition, the passive-avoidance response induced by footshocks persists for an extremely long time, being almost refractory to extinction (Ambrogi Lorenzini et al., 1986b), whereas we have shown that the response due to handling disappears easily and after a short time.

In conclusion, the present inhibition of exploratory behavior in a two-box apparatus is to be understood as a conditioned passive-avoidance response, the aversive stimulus being the handling undergone by the subjects. It must be noted that, following the laws of conditioning, the closer the two events (crossing into the goal chamber and handling) are temporally, the better the response is learned. Some conclusions may also be reached from the ancillary findings. In fact, there was a striking behavioral uniformity in spontaneous and conditioned behavior, as shown by (1) the very low values of step-through latency in Trial 1 in all 18 groups of subjects, (2) the uniform time course of the conditioned inhibition of exploratory behavior, and (3) the constant occurrence of the accompanying phenomena (grooming and attempts) in all animals handled at Time 0 in the goal chamber. This uniformity may be taken as proof that the differences observed between groups after undergoing the testing session are due to the procedures employed and not to the behavioral heterogeneity of the rats used.

It may be noted that the term "handling" covers a wide variety of procedures, so that its meaning is not definite, although it quite often indicates gentle touching or stroking of the experimental animals. The behavioral effects of this type of "gentle" handling appear to be facilitatory, generally speaking. For instance, open-field performance may be improved if preceded by gentle handling (Aulich, 
1976; Aulich \& Spielhofen, 1977; Aulich, Spielhofen, \& Raaijmakers, 1974; DeNelsky \& Denenberg, 1967a, 1967b; Joffe \& Levine, 1973; Williams \& Russell, 1972). Apart from this, it is difficult to reach any more definite conclusion regarding the "agreeableness" of gentle handling, or its "desirability." From the available reports, perhaps one of the effects of previous handling is that handled animals exhibit a decrease in fear, irrespective of the handling being gentle or comparatively rough (Eells, 1961; Spence \& Maher, 1962a, 1962b). On the other hand, our results confirm previous findings that handling, and particularly handling by the tail, has aversive characteristics, even if this handling is executed manually and as gently as possible (Black, Fowler, \& Kimbrell, 1964; Eikelboom, 1986; Fowler, 1963; McAllister, McAllister, Hampton, \& Scoles, 1980; Rigter et al., 1980; Wong, 1972). A basic difference between the experiments in which handling had a facilitatory influence and those in which, instead, it was aversive, is that in the former case handling was performed before, and sometimes a great while before, the actual experiment. In the second instance, when handling is in temporal contiguity to the behavioral test employed, the aversive characteristics of handling may increase escape (Fowler, 1963) or may increase step-through latency (Rigter et al., 1980), according to whether or not handling is performed before or after the behavior to be measured. If the results of our experiments confirm the aversive value of tail-handling, they may also help define its characteristics, in an attempt to move from a qualitative toward a quantitative assessment of it. In any experimental protocol, some type of handling is necessary. This affects the behavior of the experimental subjects to such an extent that it must be taken into account when evaluating the results.

\section{REFERENCES}

Ambrogi Lorenzini, C., Bucherelli, C., \& Giachetti, A. (1986a). Effects of goal-box detention on the exploratory behaviour of the rat. Bollettino della Società Italiana di Biologia Sperimentale, 57(Suppl. 3), 81-82.

Ambrogi Lorenzini, C., Bucherelli, C., Giachetti, A. (1986b). Some factors influencing conditioned and spontaneous behavior of rats in the light-dark box test. Physiology \& Behavior, 36, 97-101.

Ambrogi Lorenzini, C., Bucherelli, C., \& GiachetTi, A. (1987). Effects of detention and illumination on rats' exploratory behavior in a two-box apparatus. Physiology \& Behavior, 39, 103-109.

Ambrogi Lorenzini, C., Bucherell, C., Giachett, A., \& Tasson, G. (1987). Spontaneous and conditioned behavior of Wistar and Long Evans rats. Archives Italiennes de Biologie, 125, 155-170.

AULICH, D. (1976). Escape versus exploratory activity: An interpretation of rats' behavior in the open field and a light-dark preference test. Behavioral Processes, 1, 153-164.

Aulich, D., \& SPIELhofEN, J. (1977). Effects of situational complexity and repeated testing on rats' behaviour in a light-dark preference situation. Zeitschrift für Tierpsychologie, 44, 148-153.
Aulich, D., Spielhofen, J., \& RaAimmakers, G. M. (1974). The influence of adult handling and social isolation on dark preference in albino rats. Animal Behavior, 22, 987-990.

Berlyne, D. E. (1950). Novelty and curiosity as determinants of exploratory behavior. British Journal of Psychology, 41, 68-80.

BerLyNE, D. E. (1955). The arousal and satiation of perceptual curiosity in the rat. Journal of Comparative \& Physiological Psychology, 48, 238-246.

Black, R. W., Fowler, R. L., \& Kimbrell, G. (1964). Adaptation and habituation of heart rate to handling in the rat. Journal of Comparative \& Physiological Psychology, 57, 422-425.

COREY, D. T. (1978). The determinants of exploration and neophobia. Neuroscience \& Biobehavioral Reviews, 2, 235-253.

DeNelsky, G. Y., \& Denenberg, V. H. (1967a). Infantile stimulation and adult exploratory behavior: Effects of handling upon tactual variation-seeking. Journal of Comparative \& Physiological Psychology, 63, 309-312.

DeNelsky, G. Y., \& Denenberg, V. H. (1967b). Infantile stimulation and adult exploratory behavior in the rat: Effects of handling upon visual variation-seeking. Animal Behavior, 15, 568-573.

EelLS, J. F. (1961). Inconsistency of early handling and its effect upon emotionality in the rat. Joumal of Comparative \& Physiological Psychology, 54, 690-693.

EIKELBOOM, R. (1986). Learned anticipatory rise in body temperature due to handling. Physiology \& Behavior, 37, 649-653.

Fowler, H. (1963). Exploratory motivation and animal handling: The effect on runway performance of start-box exposure time. Journal of Comparative \& Physiological Psychology, 56, 866-871.

Hirate, K., Kuribara, H., Takodoro, S. (1988). Breeder differences within Wistar strain rats in acquisition of discrete shuttle avoidance response and in sensitivity to chlorpromazine. Japanese Journal of Pharmacology, 47, 209-216.

JoFFe, J. M., \& LEvine, S. (1973). Effects of weaning age and adult handling on avoidance conditioning, open field behavior, and plasma corticosterone of adult rats. Behavioral Biology, 9, 235-244.

MCAllister, D. E., McAllister, W. R., HAMPton, S. R., \& SCOLES, M. T. (1980). Escape-from-fear performance as affected by handling method and an additional CS-shock treatment. Animal Learning \& Behavior, 8, 417-423.

RabedeAU, R., \& Miles, R. C. (1959). Response decrement in visual exploratory behavior. Journal of Comparative \& Physiological Psychology, 52, 364-367.

Rigter, H., Jensen, R. A., Martinez, J. L., JR., Messing, R. B, VASQUEZ, J. B., LiANG, K. C., \& MCGAUGH, J. L. (1980). Enkephalin and fear-motivated behavior. Proceedings of the National Academy of Sciences, 77, 3729-3732.

SPENCE, J. T., \& MAHER, B. A. (1962a). Handling and noxious stimulation of the albino rat: 1 . Effects on subsequent emotionality. Journal of Comparative \& Physiological Psychology, 55, 247-251.

SPENCE, J. T., \& MAHER, B. A. (1962b). Handling and noxious stimulation of the albino rat: 2 . Effects on subsequent performance in a learning situation. Journal of Comparative \& Physiological Psychology, 55, 252-255.

TUKEY, J. W. (1949). Comparing individual means in the analysis of variance. Biometrics, 5, 99-114.

Willuams, D. I., \& RUSSELL, P. A. (1972). Open-field behavior in rats: Effects of handling, sex and repeated testing. British Journal of Psychology, 63, 593-596.

WONG, R. (1972). Infantile handling and sex as determinants of the negative reinforcing effects of gentling. Psychologische Forschung, 35, 213-217.

(Manuscript received November 22, 1988; revision accepted for publication May $7,1989$. 